\title{
Pengaruh Waktu Perendaman terhadap Daya Serap Air dan Kekuatan Tekan Komposit Batu Kapur/HDPE
}

\author{
M A Malik I Kamka ${ }^{1)}$, N P G Suardana ${ }^{* *}$, \& C I P K Kencanawati ${ }^{1)}$ \\ ${ }^{1)}$ Program Studi Teknik Mesin Fakultas Teknik Universitas Udayana \\ *) Corresponding author : npgsuardana@unud.ac.id
}

\begin{abstract}
Abstrak
Penelitian ini berupaya mengurangi jumlah limbah plastik dengan pembuatan paving block menggunakan limbah kantong plastik. Paving juga diminta tahan terhadap gerusan air hujan dan memiliki kuat tekan yang tinggi. Bahan plastik yang digunakan dalam penelitian ini adalah tipe kantong plastik HDPE (High Density Polyethylene) yang sudah dicacah hingga menjadi serpihan kecil, limbah batu kapur kemudian dicacah dan diayak dengan butiran $3 \mathrm{~mm}$ dan 10mm. Proses pencampuran sampah plastik dengan batu kapur menggunakan mesin pengaduk dengan komposisi plastik: batu kapur 3mm: batu kapur 10mm (1: 2 $1 / 2: 1 / 2$ dan 1: $41 / 2: 1 / 2$ ) dengan suhu pemanasan $200^{\circ} \mathrm{C}$ kemudian dicetak dengan mesin press. Spesimen kemudian direndam dengan variasi rendam selama 5 hari, 10 hari, 15 hari, dan 30 hari kemudian dilakukan uji tekan. Serapan air tertinggi didapatkan pada campuran perbandingan plastik dengan batu kapur 3mm dan batu kapur 10mm 1: 4 1/2 : 1/2 sebesar rata-rata serapan 1,6\%. Pengaruh perendaman mengakibat penurunan kekuatan hingga kerusakan pada spesimen setelah dilakukan uji tekan. Kuat tekan rata-rata 21,29 MPa didapatkan dari campuran plastik dengan batu kapur 3mm dan batu kapur 10mm 1: 2 1/2: 1/2 dengan lama perendaman 30 hari. Semakin lama perendaman membuat kuat tekan menurun.
\end{abstract}

Abstract

This study seeks to reduce the number of plastic bags by making paving blocks using plastic waste. Paving is also asked to withstand rainwater scouring and has high compressive strength. The plastic material used in this study is HDPE (High Density Polyethylene) plastic bags type that have been chopped up to become small flakes, the limestone waste is then chopped and sieved with $3 \mathrm{~mm}$ and $10 \mathrm{~mm}$ granules. The process of mixing plastic with limestone using a mixer with a composition plastic: limestone $3 \mathrm{~mm}$ : limestone $10 \mathrm{~mm}\left(1: 21 / 2: 1 / 2\right.$ and $\left.1: 4 \frac{1 / 2}{1}: 1 / 2\right)$ with heating temperature of $200^{\circ} \mathrm{C}$ then formed with a pressing machine. The specimens were immersed for 5 days, 10 days, 15 days, and 30 days later were subjected to compressive test. The highest water absorption obtained in mixture of plastic to limestone $3 \mathrm{~mm}$ and limestone 10mm $1: 4 \mathrm{l} 1 / 2: 1 / 2$ with an average absorption of $1.6 \%$. The effect of immersion causes decrease in strength to damage to the specimen after a compressive test. The highest average of 21,29 MPa compressive strength is obtained from mixture of plastic with limestone $3 \mathrm{~mm}$ and limestone $10 \mathrm{~mm}$ 1:2 1/2:1/2 with 30 days immersion. So the longer immersion causes a decrease in compressive strength

Kata kunci: Paving blocks, plastic waste, HDPE, limestone, water absorption

\section{PENDAHULUAN}

Pemanfaatan plastik yang meluas ini dikaitkan dengan murahnya dan nyaman digunakan dan kantong plastik dibuang sebagai limbah biasanya setelah digunakan sekali saja. Juga diyakini bahwa setelah masuk ke lingkungan, kantong plastik dapat bertahan hingga 1000 tahun untuk mengalami degradasi dan karenanya menimbulkan tantangan pembuangan tanpa bisa diurai oleh sinar matahari dan atau mikroorganisme [1]. Jika tidak diolah, plastik akan menjadi masalah besar bagi lingkungan karena tidak mudah hancur dan juga menghalangi air meresap ke dalam tanah. Salah satu kemungkinan mengurangi jumlah limbah plastik yang banyak di lingkungan adalah digunakan dalam pembuatan paving [2]
Limbah plastik yang digunakan berfungsi untuk mengganti penggunaan dari semen dalam pembuatan paving. Paving harus memiliki kuat tekan yang tinggi untuk mampu menahan beban kendaraan diatasnya. Paving juga diminta tahan terhadap gerusan air hujan agar paving tidak getas.

Dalam hal ini maka ada beberapa permasalahan yang akan dikaji, yaitu:

1. Bagaimana pengaruh waktu perendaman terhadap daya serap air pada variasi komposisi limbah plastik jenis HDPE dan batu kapur?

2. Bagaimana pengaruh waktu perendaman terhadap uji tekan pada variasi komposisi limbah plastik jenis HDPE dan batu kapur?

Beberapa batasan ditetapkan dalam penelitian ini meliputi: 
1. Batu kapur yang digunakan berasal dari limbah sisa batu kapur tempel di daerah bukit Kuta selatan-Bali.

2. Plastik dari tipe kantung plastik yang diasumsikan berasal limbah murni tanpa bahan tambahan.

\section{LANDASAN TEORI}

Paving block adalah suatu komposisi bahan bangunan yang terbuat dari campuran semen, air dan agregat. HDPE merupakan bahan plastik yang aman untuk digunakan karena kemampuan untuk mencegah reaksi kimia antara kemasan plastik dengan makanan atau minuman yang dikemasnya. HDPE memiliki sifat bahan yang lebih kuat, keras, buram dan lebih tahan terhadap suhu tinggi. Pengertian bahan komposit berarti terdiri dari dua atau lebih bahan yang berbeda yang digabung atau dicampur secara makroskopis menjadi suatu bahan yang berguna karena bahan komposit merupakan bahan gabungan secara makro. Bahan komposit secara umum terdiri dari penguat dan matrik. Matrik dalam teknologi komposit didefinisikan sebagai suatu bahan yang berfungsi sebagai pengisi dan pengikat yang mendukung, melindungi dan dapat mendistribusikan beban dengan baik ke bahan penguat komposit. Ketahanan material komposit pada lingkungan yang berair sangat ditentukan oleh kemampuan komposit untuk menyerap air dari lingkungan. Semakin banyak air yang diserap menunjukkan ikatan interfacial serat dan matriks yang kurang kuat, begitu juga sebaliknya.

Persentasenya dengan menggunakan persamaan sesuai dengan ASTM D570 sebagai berikut:

$$
\text { Serapan Air }=\frac{(\text { berat basah-berat awal) }}{\text { berat awal }} \times 100 \%
$$

Uji tekan memiliki kinerja yang bagus dan berkualitas untuk mengetahui kekuatan benda.

Kuat tekan dihitung dengan menggunakan rumus sesuai dengan ASTM D790 sebagai berikut:

$$
\sigma=\frac{P}{A}
$$

dimana:

$\mathrm{P}$ : beban tekan $(\mathrm{kN})$

A: luas penampang $(\mathrm{cm})$

\section{METODOLOGI PENELITIAN}

Adapun bahan utama penelitian yang akan digunakan adalah:

1. Plastik yang digunakan dalam penelitian ini adalah jenis $H D P E$ tipe kantong plastik yang sudah dibersihkan dan dicacah hingga menjadi serpihan kecil.

2. Batu kapur yang digunakan dalam proses pembuatan spesimen yaitu limbah pengrajin batu kapur sebelum digunakan dibersihkan terlebih dahulu dan dihilangkan debu kemudian dicacah dan diayak dengan butiran $3 \mathrm{~mm}$ dan $10 \mathrm{~mm}$.

\section{Pembuatan Komposit}

1. Langkah pertama batu kapur dicuci untuk menghilangkan debu dan bahan pengotor lainnya kemudian dikeringkan secara alami di bawah sinar matahari selama 24 jam.

2. Sampah plastik kemudian dibersihkan dari debu kotoran kemudian dikeringkan di bawah sinar matahari

3. Pencacahan bahan plastik bekas dengan mesin pencacah plastik.

4. Proses pencampuran diawali pemanasan batu kapur dengan suhu $200^{\circ} \mathrm{C}$ dilanjutkan dengan memasukkan sampah plastik kedalam mesin dengan komposisi plastik: batu kapur $3 \mathrm{~mm}$ : batu kapur 10mm (1:2 $2 \frac{1 / 2}{1 / 2}$ dan $\left.1: 41 \frac{1}{2}: 1 / 2\right)$.

5. Proses pencetakan bahan dengan mesin pres agar tidak terjadi void yang berlebih.

6. spesimen lalu dikeluarkan dari cetakan.

7. Memotong spesimen uji sesuai dengan standar ASTM D695 untuk uji tekan.

8. Pengamatan bentuk fisik komposit, komposit yang berhasil dicetak, diamati apakah ada void yang terlihat dari permukaan atau tidak.

\section{Langkah pengujian}

1. Spesimen uji yang telah dicetak dikeringkan

2. Melanjutkan dengan pengkodean

3. Spesimen uji direndam dengan variasi waktu yang ditentukan

4. Pencatatan hasil resapan air pada spesimen uji

5. Setelah dilakukan pencatatan, spesimen di uji kekuatan tekan.

\section{HASIL DAN PEMBAHASAN}

Pengambilan data hasil penelitian diambil setelah proses pencampuran bahan yaitu plastik jenis $H D P E$ 
dengan batu kapur $3 \mathrm{~mm}$ dan batu kapur $10 \mathrm{~mm}$ memakai perbandingan $1: 2 \frac{1}{2}: 1 / 2 \& 1: 41 / 2: 1 / 2$ dengan suhu pemanasan $200^{\circ} \mathrm{C}$. Selanjutnya proses pencetakan spesimen sampai pada proses pengujian uji serapan air dan uji tekan.

\subsection{Data Hasil Serapan Air}

Data hasil serapan air dilakukan dengan cara membandingkan berat sampel yang ditimbang beratnya dengan menggunakan timbangan digital dan dicatat sebagai berat awal. Sampel kemudian direndam didalam air kemudian akan diangkat sesuai dengan variasi hari yang ditentukan dan dicatat beratnya sebagai berat basah.

Berat awal $: 392$ gram
Berat basah $: 394$ gram
Serapan air $=\frac{(\text { berat basah-berat awal })}{\text { berat awal }} \times 100 \%$
Serapan air $=\frac{(394-392)}{392} \times 100 \%$
Serapan air $=0,510 \%$

Gambar 1 contoh Perhitungan Serapan Air Dengan Campuran $1: 2 \frac{1}{2}: 1 / 2$ Pada Spesimen 1

Tabel 1 data Serapan Air

\begin{tabular}{|c|c|c|c|c|c|c|}
\hline $\begin{array}{c}\text { Lama } \\
\text { Perendaman } \\
\text { (hari) }\end{array}$ & Perbandingan & Spesimen & $\begin{array}{c}\text { Berat } \\
\text { kering } \\
(\mathrm{gr})\end{array}$ & $\begin{array}{c}\text { Berat } \\
\text { basah } \\
\text { (gr) }\end{array}$ & $\begin{array}{c}\text { Persentase } \\
\text { penyerapan } \\
(\%) \\
\end{array}$ & $\begin{array}{c}\text { Rata-rata } \\
(\%)\end{array}$ \\
\hline \multirow{6}{*}{5} & \multirow{3}{*}{$1: 2 \frac{1}{2}: \frac{1}{2}$} & 1 & 392 & 394 & 0,51 & \multirow[b]{3}{*}{0,50} \\
\hline & & 2 & 409 & 411 & 0,48 & \\
\hline & & 3 & 386 & 388 & 0,51 & \\
\hline & \multirow{3}{*}{$1: 4 \frac{1}{2}: \frac{1}{2}$} & 1 & 356 & 358 & 0,56 & \multirow[b]{3}{*}{0,64} \\
\hline & & 2 & 422 & 425 & 0,71 & \\
\hline & & 3 & 450 & 453 & 0,66 & \\
\hline \multirow{6}{*}{10} & \multirow{3}{*}{$1: 2 \frac{1}{2}: \frac{1}{2}$} & 1 & 392 & 395 & 0,76 & \multirow[b]{3}{*}{0,68} \\
\hline & & 2 & 406 & 409 & 0,73 & \\
\hline & & 3 & 365 & 367 & 0,54 & \\
\hline & \multirow{3}{*}{$1: 4 \frac{1}{2}: \frac{1}{2}$} & 1 & 372 & 376 & 1,07 & \multirow[b]{3}{*}{0,85} \\
\hline & & 2 & 404 & 407 & 0,74 & \\
\hline & & 3 & 403 & 406 & 0,74 & \\
\hline \multirow{6}{*}{15} & \multirow{3}{*}{$1: 2 \frac{1}{2}: \frac{1}{2}$} & 1 & 441 & 445 & 0,90 & \multirow[b]{3}{*}{0,76} \\
\hline & & 2 & 457 & 460 & 0,65 & \\
\hline & & 3 & 405 & 408 & 0,74 & \\
\hline & \multirow{3}{*}{$1: 4 \frac{1}{2}: \frac{1}{2}$} & 1 & 384 & 390 & 1,56 & \multirow[b]{3}{*}{1,29} \\
\hline & & 2 & 420 & 425 & 1,19 & \\
\hline & & 3 & 441 & 446 & 1,13 & \\
\hline \multirow{6}{*}{30} & \multirow{3}{*}{$1: 2 \frac{1}{2}: \frac{1}{2}$} & 1 & 398 & 402 & 1,00 & \multirow[b]{3}{*}{0,94} \\
\hline & & 2 & 408 & 411 & 0,73 & \\
\hline & & 3 & 368 & 372 & 1,08 & \\
\hline & \multirow{3}{*}{$1: 4 \frac{1}{2}: \frac{1}{2}$} & 1 & 318 & 325 & 2,20 & \multirow[b]{3}{*}{1,66} \\
\hline & & 2 & 402 & 407 & 1,24 & \\
\hline & & 3 & 389 & 395 & 1,54 & \\
\hline
\end{tabular}

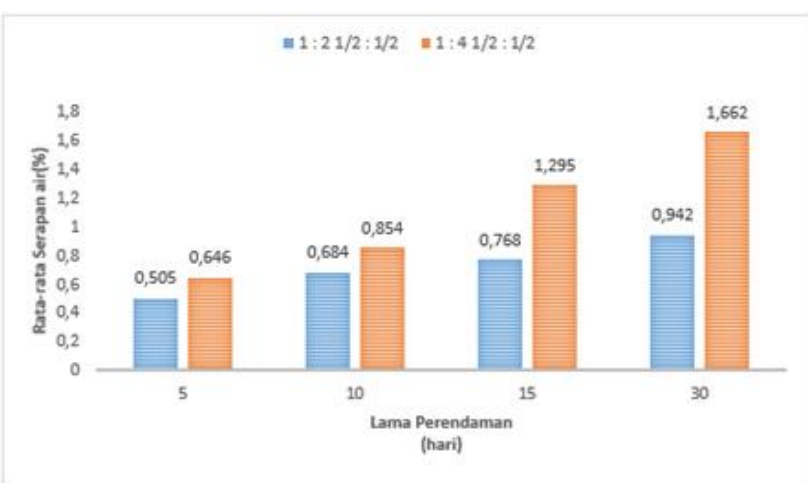

Gambar 2 grafik Rata-rata Serapan Air

\subsection{Pembahasan Uji Serapan Air}

Hasil pengukuran serapan air dengan variasi campuran plastik dengan batu kapur $3 \mathrm{~mm}$ dan batu kapur $10 \mathrm{~mm}$ yang telah dibuat menghasilkan data serapan air ratarata dari setiap sampel. Seperti diperlihatkan pada Gambar 2 menunjukan bahwa rata-rata serapan air terbesar didapatkan dari variasi campuran plastik dengan batu kapur dan kapur 1: 4 1/2:1/2 pada setiap variasi hari perendaman. Hal ini dikarenakan batu kapur pada komposit 1 : 41/2: $1 / 2$ lebih banyak dibandingkan pada komposit 1: $2 \frac{1}{2}$ : $1 / 2$ yang menyebabkan terbentuknya lebih banyak celah. Dengan komposisi batu kapur yang lebih banyak dibandingkan plastik juga memudahkan air untuk terserap oleh spesimen, maka akan lebih besar penyerapan air yang terjadi. Hal ini dapat dilihat pada hasil pengamatan pada spesimen dengan menggunakan alat uji foto mikro pada gambar $3 \& 4$.

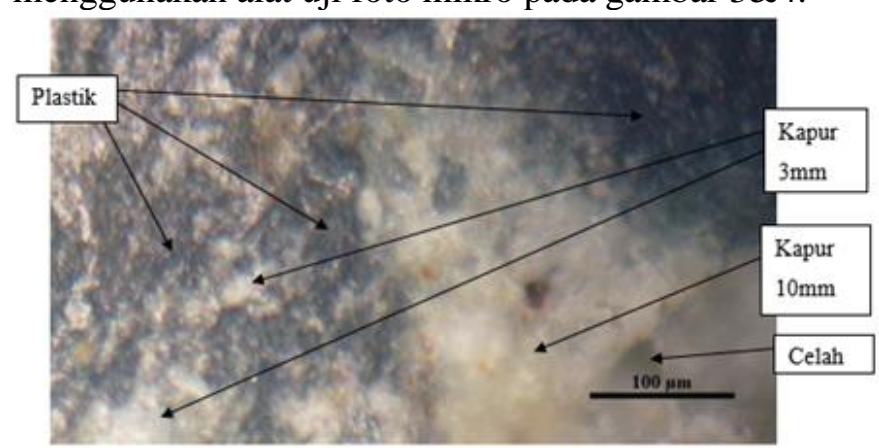

Gambar 3 hasil Uji Foto Mikro Pada Spesimen dengan campuran $1: 2 \frac{1}{2}: 1 / 2$

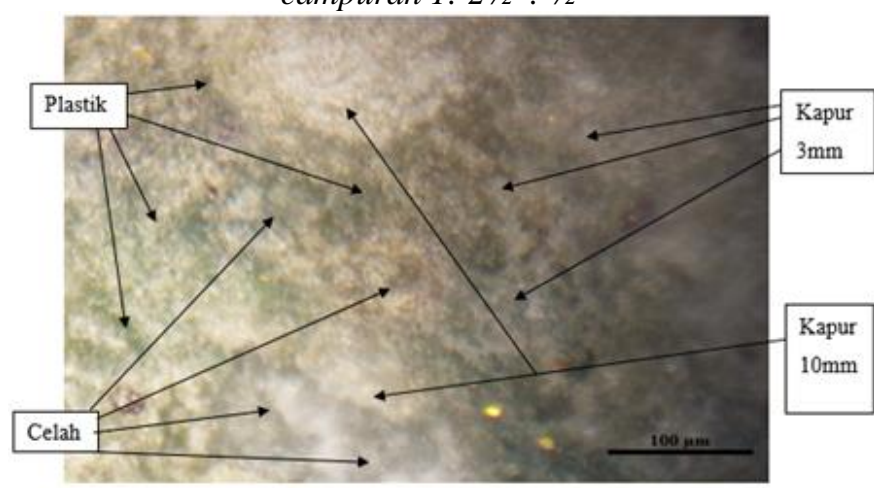

Gambar 4 hasil Uji Foto Mikro Pada Spesimen dengan campuran $1: 41 / 2: 1 / 2$

Seminar Nasional TEKNOKA ke - 5, Vol. 5, 2020 ISSN No. 2502-8782 
Seperti yang ditujukan pada Gambar 3 terdapat lebih banyak plastik dibanding batu kapur dan terdapat sedikit celah pada permukaan spesimen yang menyulitkan air untuk masuk terserap. Berbeda dengan Gambar 4 dengan komposisi plastik yang lebih sedikit dan terdapat lebih banyak batu kapur yang membuat celah-celah diantara ikatan plastik pada permukaan spesimen untuk menyerap air lebih banyak. Paving block yang tidak menggunakan limbah plastik menyerap air lebih banyak karena limbah plastik sangat buruk dalam menyerap air dan bahkan menolak penyerapan air [3].

\subsection{Data Hasil Pengujian Tekan}

Pengambilan data uji tekan dilakukan setelah pencetakan dan perlakuan peredaman spesimen kemudian di uji tekan dengan menggunakan alat mortar compression machine UT200/50EL untuk mengetahui kuat tekan paving.

$$
\begin{aligned}
& \text { Beban Tekan : } 105(\mathrm{KN}) \\
& \text { Luas Penampang : } 36 \mathrm{~cm}^{2} \\
& \sigma=\frac{P}{A} \\
& =\frac{105(K N)}{(36 \div 10.000) m^{2}} \\
& =\frac{105(\mathrm{KN})}{0,0036\left(\mathrm{~m}^{2}\right)} \\
& =29.166 .67\left(\mathrm{KN} / \mathrm{m}^{2}\right) \div 1.000 \\
& =29,16(\mathrm{MPa})
\end{aligned}
$$

\begin{tabular}{|c|c|c|c|c|c|c|}
\hline $\begin{array}{l}\text { Perbandingan } \\
\text { plastik dengan } \\
\text { batu kapur } \\
3 \mathrm{~mm} \text { dan batu } \\
\text { kapur } 10 \mathrm{~mm}\end{array}$ & $\begin{array}{c}\text { Lama } \\
\text { perendaman } \\
\text { (bari) }\end{array}$ & Sampel & $\begin{array}{l}\text { Beban } \\
\text { Tekan } \\
(\mathrm{KN})\end{array}$ & $\begin{array}{c}\text { Luas } \\
\text { Renampang } \\
\left(\mathrm{Cm}^{2}\right)\end{array}$ & $\begin{array}{c}\text { Kuat Tekan } \\
(\mathrm{MPa})\end{array}$ & $\begin{array}{l}\text { Rata- } \\
\text { rata } \\
(\mathrm{MPa})\end{array}$ \\
\hline \multirow{15}{*}{$1: 2 \frac{1}{2}: \frac{1}{2}$} & \multirow{3}{*}{$\begin{array}{c}\text { Tanpa } \\
\text { Rerendaman }\end{array}$} & Specimen 1 & 100 & 36 & 27,77 & \multirow{3}{*}{28,24} \\
\hline & & Specimen 2 & 105 & 36 & 29,16 & \\
\hline & & Specimen 3 & 100 & 36 & 27,77 & \\
\hline & \multirow{3}{*}{5 hasi } & Specimen 1 & 105 & 36 & 29,16 & \multirow{3}{*}{27,77} \\
\hline & & Specimen 2 & 105 & 36 & 29,16 & \\
\hline & & Specimen 3 & 90 & 36 & 25 & \\
\hline & \multirow{3}{*}{10 hari } & Specimen 1 & 70 & 36 & 19,44 & \multirow{3}{*}{25} \\
\hline & & Specimen 2 & 120 & 36 & 33,33 & \\
\hline & & Specimen 3 & 80 & 36 & 22,22 & \\
\hline & \multirow{3}{*}{15 hari } & Specimen 1 & 90 & 36 & 25 & \multirow[t]{3}{*}{23,61} \\
\hline & & Specimen 2 & 85 & 36 & 23,61 & \\
\hline & & Specimen 3 & 80 & 36 & 22,22 & \\
\hline & \multirow{3}{*}{30 hari } & Specimen 1 & 85 & 36 & 23,61 & \multirow{3}{*}{21,29} \\
\hline & & Specimen 2 & 75 & 36 & 20,83 & \\
\hline & & Specimen 3 & 70 & 36 & 29,16 & \\
\hline
\end{tabular}

\begin{tabular}{|c|c|c|c|c|c|c|}
\hline \multirow{15}{*}{ 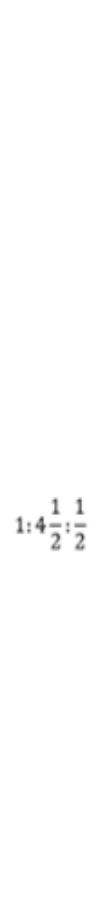 } & \multirow{3}{*}{$\begin{array}{c}\text { Tanpa } \\
\text { Perendaman }\end{array}$} & Specimen 1 & 90 & 36 & 25 & \multirow{3}{*}{26,85} \\
\hline & & Specimen 2 & 100 & 36 & 27,77 & \\
\hline & & Specimen 3 & 95 & 36 & 26,38 & \\
\hline & \multirow{3}{*}{5 hari } & Specimen 1 & 85 & 36 & 23,61 & \multirow{3}{*}{26,38} \\
\hline & & Specimen 2 & 90 & 36 & 25 & \\
\hline & & Specimen 3 & 110 & 36 & 30,55 & \\
\hline & \multirow{3}{*}{10 hari } & Specimen 1 & 85 & 36 & 23,611 & \multirow{3}{*}{24,07} \\
\hline & & Specimen 2 & 85 & 36 & 23,611 & \\
\hline & & Specimen 3 & 90 & 36 & 25 & \\
\hline & \multirow{3}{*}{15 hari } & Specimen 1 & 80 & 36 & 22,22 & \multirow{3}{*}{21,75} \\
\hline & & Specimen 2 & 80 & 36 & 22,22 & \\
\hline & & Specimen 3 & 70 & 36 & 19,44 & \\
\hline & \multirow{3}{*}{30 hari } & Specimen 1 & 75 & 36 & 20,83 & \multirow{3}{*}{20,37} \\
\hline & & Specimen 2 & 70 & 36 & 19,44 & \\
\hline & & Specimen 3 & 75 & 36 & 20,83 & \\
\hline
\end{tabular}

Gambar 5 contoh Perhitungan Kuat Tekan Paving Dengan Campuran 1: 21/2:1/2 Pada Spesimen 1

Tabel 2 data Kuat Tekan
$\|1: 21 / 2: 1 / 2 \quad\| 1: 41 / 2: 1 / 2$

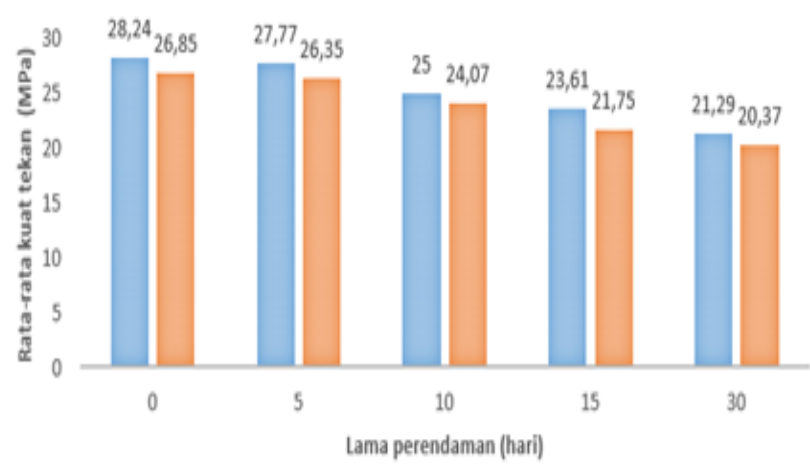

Gambar 6 grafik Rata-rata Kuat Tekan

\subsection{Pembahasan Uji Tekan}

Data menunjukan bahwa perbedaan variasi perendaman dan campuran plastik dengan batu kapur $3 \mathrm{~mm}$ dan batu kapur $10 \mathrm{~mm}$ berpengaruh terhadap kuat tekan paving. Berdasarkan hasil pengukuran, kuat tekan rata-rata tertinggi dimiliki oleh sampel dengan perbandingan plastik dengan batu kapur $3 \mathrm{~mm}$ dan batu kapur $10 \mathrm{~mm} 1: 2^{1 / 2}: 1 / 2$ pada setiap variasi waktu perendaman. Berbeda pada perbandingan 1 : $4 \frac{1}{2}: 1 / 2$ yang memiliki kandungan plastik lebih sedikit dan batu kapur yang banyak membuat celahcelah diantara ikatan plastik terbukti memiliki kuat tekan lebih kecil pada setiap variasi waktu perendaman. 


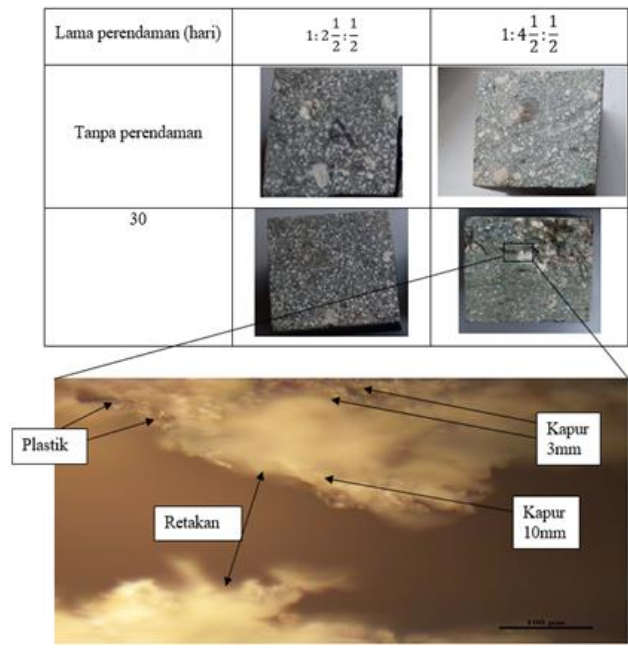

Gambar 7 perbandingan Spesimen Hasil Uji Tekan dengan Uji Foto Mikro

Gambar 7 memperlihatkan perbandingan yang terjadi ketika spesimen di rendam dan diuji tekan. Dapat dilihat komposisi spesimen $1: 2 \frac{1}{2}: 1 / 2$ perendaman 30 hari, kuat tekan spesimen yang menurun akibat perendaman namun tidak terjadi retakan yang terlihat pada permukaan spesimen. Berbeda dengan spesimen $1: 4 \frac{1}{2}: 1 / 2$ perendaman 30 hari, kuat tekan spesimen yang menurun karena batu kapur pada spesimen yang meresap air melalui celah-celah hingga ikatan plastik dengan batu kapur terjadi kerusakan pada spesimen yang membuktikan terjadi pengurangan kekuatan pada penguat yang berupa batu kapur sehingga tidak lagi terikat pada plastik. Kuat tekan material komposit berkurang selama periode perendaman karena material komposit menyerap air yang kemudian mengurangi kuat tekan material [4]. semakin tinggi komposisi batu kapur pada campuran plastik dan batu kapur, semakin rendah kekuatan tekan yang dihasilkan [5].

\section{SIMPULAN}

1. Dengan banyaknya komposisi batu kapur juga membuat spesimen memiliki celah bagi air untuk meresap masuk. Semakin lama perendaman komposit membuat semakin besar hasil serapan air yang didapat. Serapan air tertinggi didapatkan pada campuran perbandingan plastik dengan batu kapur $3 \mathrm{~mm}$ dan batu kapur 10mm 1: 4 1/2: $: 1 / 2$ dengan lama perendaman 30 hari sebesar rata-rata serapan $1,6 \%$. Sedangkan serapan air pada perbandingan $1: 2 \frac{1}{2}: 1 / 2$ perendaman 30 hari hanya sebesar rata-rata serapan air $0,9 \%$.

2. Kuat tekan rata-rata $21,29 \mathrm{MPa}$ didapatkan dari campuran plastik dengan batu kapur $3 \mathrm{~mm}$ dan batu kapur 10mm 1: 2 1/2:1/2 dengan lama perendaman 30 hari. Pengaruh variasi perendaman pada komposisi batu kapur mengakibat penurunan kekuatan hingga erusakan pada spesimen setelah dilakukan uji tekan. Kuat tekan rata-rata tertinggi didapatkan dari campuran plastik dengan batu kapur 3mm dan batu kapur 10mm $1: 21 \frac{1}{2}: 1 / 2$ pada setiap waktu perendaman dibandingkan $1: 4 \frac{1 / 2}{2}: 1 / 2$. Semakin lama waktu perendaman kedua perbandingan spesimen mengakibatkan penurunan kuat tekan.

\section{ACKNOWLEGMENT}

Penelitian ini dibiayai oleh DIPA PNBP Universitas Udayana TA-2020 sesuai dengan Surat Perjanjian Penugasan Pelaksanaan Penelitian

Nomor : B/20-38/UN14.4.A/PT.01.05/2020, tanggal 10 maret 2020

\section{KEPUSTAKAAN}

[1] Moharam, Riyad., Maher Ali. Al. Maqtari2, 2014. International Journal of Engineering Research and Reviews ISSN 2348-697X (Online) ( Vol. 2, Issue 4, pp: (61-69) ) Website: www.researchpublish.com

[2] Chavan, S., Shubham Tamhane2, Mukesh Chavan3, Rushikesh Phuge4, Prof.Mayur Tanpure5, Prof. Manoj Deosarkar6, 2019. International Journal of Innovative Research in Science, Engineering and Technology (A High Impact Factor, Monthly, Peer Reviewed Journal) www.ijirset.com Vol. 8.

[3] Agyeman, S., Obeng-Ahenkora, N.K., Assiamah, S., Twumasi, G., 2019. Exploiting Recycled Plastic Waste as an Alternative Binder for Paving Blocks Production. Case Studies in Construction Materials 11. Elsevier

[4] Quarcoo. F ,The Use of Low Linear Density Polyethylene in the Production of LDPE-SandStone Composites Kwame Nkrumah University of Science and Technology, Kumasi, Ghana (2015).

[5] Mashudi. I, N P G Suardana, I N Arya Thanaya, I W Bandem Adnyana, and C I P K Kencanawati, 2019, Compressive strength and truck run over ability of plastic/sand paving block composites. IOP Conf. Series: Materials Science and Engineering839 (2020) 012011. 